\title{
Ruimte voor structureel gebruik van muziek en poëzie in het taalverwervingsonderwijs NVT in Centraal-Europa
}

\begin{abstract}
This paper deals with the potential of the systematic use of authentic texts presented via songs and poetry to the students of Dutch as a foreign language studying at universities in Central Europe. Based on the positive experience with these materials, which is believed to be relevant also to other foreign languages than Dutch, the article advocates a much broader and more intensive exploitation of such materials. This research combines literature study and examples of good practice observed at one of the universities in the Czech Republic offering a Dutch studies programme. Within the framework of the specific research questions, it also discusses the relevance of songs and poetry to foreign language teaching. Additionally, it provides a detailed overview of the elements concerning the systematic way of exploiting songs and poetry within a specific Dutch language course.
\end{abstract}

Keywords: songs, poetry, teaching Dutch as a foreign language, curriculum, motivation, effectiveness.

\section{Inleiding}

Net zoals het bij andere talen het geval is, kent ook het onderwijs Nederlands als Vreemde Taal (NVT) aan Centraal-Europese universiteiten zeer gevarieerde vormen (Blell e.a. 1996; Janíková 2000; Jauregi e.a. 2011; Křŕž 2014, 2015, 2016a, 2016b). Toch blijven er in de eerste jaren van de bachelorstudie NVT vele kansen onbenut. Met betrekking tot het taalverwervingsonderwijs - traditioneel één van de steunpilaren van het NVT-onderwijs - betreft dit authentiek materiaal in de vorm van liedjes en poëzie. Hiervan wordt binnen de neerlandistiek nauwelijks gebruik gemaakt, al maken moderne leergangen als Nederlands in actie wel incidenteel gebruik van liedjes. Overigens is binnen het basisonderwijs en onderwijs 
Engels als tweede/vreemde taal het gebruik van muziek ter ondersteuning van het taalonderwijs wel al sinds de jaren zestig relatief gebruikelijk (Engh 2013: 113; Rosová 2007). Voor het Nederlands is met name in het onderwijs Nederlands als tweede taal aan migranten recentelijk veel materiaal met liedjes ontwikkeld (naast Reekmans e.a. 2017: 49-57; zie bijvoorbeeld Kuiken \& Burgers 2018).

Over de achtergrond van docenten die het incidentele gebruik van liedjes in het taalverwervingsonderwijs als een gemiste kans beschouwen, vaak omdat ze zelf actief muzikanten zijn of waren en daardoor op een natuurlijke manier gedreven worden om liedjes (tevens een vorm van poëzie) in hun taalverwervingsonderwijs te benutten, staat voor het Nederlands meer in Kř́žz (2016b) en voor het Engels in Engh (2013: 119-120). Beide artikelen bevatten ook gedetailleerde informatie over onderzoeksprojecten gericht op het gebruik van muziek in het vreemdetaal- respectievelijk tweedetaalonderwijs. Het gebruik van muziek in het NVT-onderwijs was in 2017 en 2018 overigens ook een onderdeel van de nascholingscursus van de Nederlandse Taalunie voor docenten (www1).

Zoals Engh (2013: 113) aangeeft, "there is sometimes a lack of the theoretical underpinnings that support such a choice". En de keus om liedjes en muziek in het onderwijs te gebruiken is voor docenten moderne vreemde talen niet altijd voor de hand liggend. Toch is recent in een heel ander onderzoeksveld een interessant argument vóór deze keus aangereikt. In februari 2017 heeft namelijk Richard Kunert in Nijmegen zijn dissertatie Music and Language Comprehension in the Brain verdedigd. Hierin doet hij onderzoek naar de door Patel (2008) voor het eerst geponeerde shared syntactic integration resource hypothesis. Deze hypothese stelt dat het menselijk brein niet alleen dezelfde regionen gebruikt voor muziek en taal, maar dat er bovendien overeenkomsten zijn in breinactiviteit tussen muzikale en syntactische structuren, zodat deze twee vermoedelijk met elkaar in verband staan. Kunert heeft in zijn dissertatie-onderzoek deze in de afgelopen tien jaar met name door psycholinguïsten en neuropsychologen gepropageerde hypothese aan systematisch empirisch onderzoek onderworpen. Zijn conclusie is dat muzikale structuren en talige syntactische structuren duidelijk hetzelfde neurale circuit in de achterste hersenregionen (het zogenaamde gebied van Broca) activeren, maar dat op dit moment nog niet precies kan worden vastgesteld hoe zij onderling met elkaar samenhangen (Kunert 2017: 201-202).

Hoewel de twee onderzoeksvelden vooralsnog van elkaar gescheiden lijken te zijn - Kunert en Patel verwijzen in hun werken niet naar didactische publicaties en omgekeerd verwijzen de hierboven aangehaalde pedagogische publicaties niet naar werk van psycholinguïsten en neuropsychologen ${ }^{1}$ - is het duidelijk dat er een verband is. Deze conclusie sluit aan bij wat de auteur van dit artikel heeft vastgesteld bij positieve resultaten van het systematisch werken met liedjes door stu-

${ }^{1}$ Hierbij moet worden opgemerkt dat Kunerts onderzoek is opgemerkt en bediscussieerd door de redactie van Didactief (www2). 
denten in colleges taalverwerving aan de Palacký Universiteit te Olomouc en bij resultaten van soortgelijke onderzoeken naar het gebruik van liedjes in het Engels of Duits (Engh 2013; Goodlad 1979; Janíková 2000; Rosová 2007). Ook het Netwerk voor Nederlands Onderwijs Wereldwijd (NOB) biedt sinds kort een cursus Creatief met Taal aan, waarin onder leiding van Peter Schoenaerts en Helga van Loo muziek in de vorm van liedjes ter ondersteuning van cursussen NT2 en NVT als lesmateriaal wordt aangeboden aan docenten van het basisonderwijs (www3).

Als het gebruik van muziek dan kennelijk positief is, er minimaal in het Engels veel gebruik van wordt gemaakt in het basisonderwijs en onderwijs Engels als vreemde taal en de laatste jaren in toenemende mate muziek ook wordt ingezet als aanvulling binnen het onderwijs NT2 voor migranten, rijst de vraag hoeveel ruimte er in het curriculum NVT op universitair niveau is of moet zijn voor de verbinding van muziek en taal door het systematisch gebruik van authentieke teksten in liedjes en poëzie. Deze doelgroep verschilt duidelijk van de hierboven vermelde groepen. Het gaat hier om een groep hoger opgeleide studenten, die in het buitenland een vreemde taal leren. Het merendeel van deze studenten heeft bovendien al actieve ervaring met het leren van minimaal één vreemde taal - meestal het Engels.

\section{Onderzoeksvragen}

De onderzoeksvraag luidt dus: Dient er in het universitair curriculum moderne vreemde talen ruimte te zijn voor (systematisch gebruik van) liedjes en poëzie? En zo ja, hoeveel? De voornaamste conclusie van het promotieonderzoek van de auteur van dit artikel uitgevoerd bij de Universiteit Utrecht naar de effectiviteit van het NVT-onderwijs aan universiteiten in Centraal-Europa is dat er vele wegen naar effectief onderwijs zijn. Hierbij moet vooral de kwaliteit van de docent(en) centraal staan (Kř́žz 2014: 163-164). Gesteld mag worden dat een goed geschoolde en enthousiaste docent die over ruimte en middelen beschikt om zijn visies idealiter in nauw overleg met zijn collega's - te verwezenlijken, een aanzienlijk verschil kan maken. Hierbij is van belang, dat elke docent het beste en het liefst op de manier werkt, die goed bij hem past.

Bovengestelde onderzoeksvraag valt uiteen in een serie subvragen. De eerste subvraag is: Waarom zou deze ruimte er moeten zijn? Op deze vraag zijn verschillende antwoorden mogelijk die variëren van de noodzaak ter afwisseling van de inhouden en de didactische aanpak van de docent tot het versterken of verankeren van bepaalde elementen. Een niet te onderschatten reden voor het (systematisch) implementeren van liedjes en poëzie heeft ongetwijfeld ook met het vergroten van de motivatie van de studenten te maken. Wanneer de studenten door middel van de keuze van bijvoorbeeld een eigen liedje de inhouden van bepaalde onderdelen 
van hun cursus kunnen bepalen, heeft het logischerwijze positief effect. Dit effect blijft bovendien niet beperkt tot de studenten die de keuze hebben gemaakt. Zoals blijkt uit de ervaringen van de hieronder in paragraaf 3 beschreven casestudie, voelen de studenten zich vaak meer aangesproken door de keuzes van hun medestudenten dan door de keuzes die hun docent maakt. Hierbij speelt niet alleen de onderlinge solidariteit van de studenten een rol, maar ook het feit, dat de studenten weten dat ze op termijn ook met hun eigen liedjes aan de beurt kunnen komen. Aan de hieronder in de casestudie beschreven universitaire opleiding wordt namelijk de mogelijkheid benut om de studenten medeverantwoordelijk te maken voor de voorbereiding van het te gebruiken cursusmateriaal en voor de uiteindelijke uitvoering van het desbetreffende cursusonderdeel. Deze voorbeelden van activerende werkvormen dienen idealiter een vast, voor de studenten vertrouwd patroon te volgen, zodat ze voor de studenten als een houvast kunnen fungeren. Vanzelfsprekend mag gedurende het hele proces van voorbereiding en uitvoering van deze cursusonderdelen de systematische ondersteuning van de docent niet ontbreken. Het uiteindelijke effect van deze voorbeelden van activerende werkvormen kan nog worden versterkt door het maken en achteraf nabespreken van video-opnames van de desbetreffende op liedjes gebaseerde cursusonderdelen. Deze cursusonderdelen dienen dan ook proportioneel in de afsluitende test worden vertegenwoordigd.

Met de proportionaliteit van de cursusonderdelen hangt ook de volgende subvraag samen: Hoeveel ruimte is er voor liedjes en poëzie? Hierbij wordt op basis van Kříž (2014: 21-39) een onderscheid gemaakt tussen het Theoretisch curriculum en het Operationeel curriculum. Onder theoretisch curriculum wordt verstaan het curriculum, zoals het formeel voor de studierichting beschreven is. Een belangrijk verschil van het universitair onderwijs met primair en secundair onderwijs is bijvoorbeeld dat accreditatiecommissies in toenemende mate de nadruk leggen op de theoretische kant van het onderwijs. Dit gebeurt vaak ten koste van als "niet-academisch" beschouwde praktische vaardigheden, bijvoorbeeld tolken en vertalen. Het gebruik van liedjes en poëzie in het taalonderwijs kan onder deze omstandigheden dan ook onder vuur komen liggen. Het operationeel curriculum betreft de specifieke uitvoering van het theoretisch curriculum in de praktijk. Hierbij dient opgemerkt te worden, dat dit altijd een samenspel is van activiteiten van de docent, de studenten en van externe factoren zoals kwaliteit, uitrusting en beschikbaarheid van de onderwijsruimte. Deze factoren worden de randvoorwaarden met invloed op de didactische aanpak genoemd en vormen een onderdeel van de organisatorische inbedding. Samen met inhoud van het curriculum en de didactische aanpak zijn dit de drie pijlers van het genoemde promotieonderzoek (Kř́ž 2014: 163-164).

De derde vraag betreft de autoriteit die over het gebruik van liedjes en poëzie beslist. Is het de landelijke accreditatiecommissie, het hoofd van de vakgroep, de 
werkgroep van docenten of nog iemand anders? Bij het structureel gebruik van liedjes en poëzie gaat het niet om het ontwikkelen van cursussen die uitsluitend op het gebruik van deze bronnen gebaseerd zouden zijn. ${ }^{2}$ Toch kan het voor de docenten een enorme uitdaging zijn om de collega's die nut en noodzaak van het systematische gebruik van liedjes en poëzie niet kunnen en/of willen zien, te overtuigen dat het geen tijdsverspilling is. Hetzelfde, soms moeizame, gevecht kan zich natuurlijk afspelen ook tussen de docent en de leidinggevenden in de opleiding.

Hier spelen ook de organisatorische aspecten die bij het implementeren van liedjes en poëzie in de cursussen taalverwerving horen, een rol. Gaat het slechts om ad hoc activiteiten of worden de liedjes en poëzie op structurele wijze in de gehele cursus toegepast met gebruikmaking van gestandaardiseerde protocollen? Deze laatste benadering heeft een aanzienlijk groter effect vergeleken met een incidentele aanpak.

Hiermee hangt ook nauw samen in welke periode liedjes en poëzie in de cursussen taalverwerving aan bod komen. Krijgen ze alleen ruimte in het begin of juist tegen het einde van het studiejaar om voor de afwisseling in de cursus te zorgen? Of worden ze toegepast op momenten wanneer er inhoudelijk aanleiding voor is? Of misschien fungeren ze als een vast onderdeel van de colleges van de desbetreffende docent. Aan de hand van de in paragraaf 3 beschreven casestudie Olomouc tracht de auteur van dit artikel een indicatie te geven dat de hierboven geformuleerde onderzoeksvraag en subvragen positief beantwoord kunnen worden. En dat structureel gebruik van liedjes en poëzie in de praktijk gerealiseerd kan worden. Met betrekking tot de voorbeelden van de brede schaal aan specifieke didactische werkvormen kan worden verwezen naar de in de bibliografie opgenomen bronnen.

\section{Casestudie Olomouc - mogelijke bron van inspiratie}

Hoewel taalverwervingsonderwijs ongetwijfeld ook zonder liedjes en poëzie kan functioneren, is het de moeite waard om te onderzoeken, wat het potentieel van deze elementen voor het verbeteren van dit onderwijs is. Vanwege de beschikbaarheid van onderzoeksdata maakt de auteur hierbij gebruik van zijn eigen NVT-onderwijs als casestudie. Deze keuze hangt er onder andere mee samen dat hij al twee decennia lang het potentieel van liedjes ter verbetering van het onderwijs in moderne vreemde talen onderzoekt. Wegens de lage aantallen van studenten en de overige organisatorische aspecten is het echter spijtig genoeg niet mogelijk om voor dit onderzoek een controlegroep van voldoende grootte in te stellen. Wanneer er studenten

${ }^{2}$ Zulke cursussen kunnen als een aanvullende keuzevak voor geïnteresseerde studenten worden aangeboden. 
zouden zijn die het Nederlands zonder gebruik van liedjes en poëzie van dezelfde docent aangeboden zou krijgen, dan zou de validiteit van de uitkomsten van dit onderzoek vanzelfsprekend aanzienlijk groter zijn.

Toen de auteur in februari 2000 als invaller aan de universiteit kwam werken, nam hij de audio-lexicale methode Spreken is zilver in combinatie met de leergang Nederlied over van zijn collega's. Deze leergangen waren kort daarvoor geïntroduceerd in samenwerking met de Stichting Stimulering Audio-Lexicaal Taalonderwijs (hierna: SSALTO). De auteur van dit artikel was destijds zelf bezig met het implementeren van beide leergangen aan het Slovanské gymnázium Olomouc, waar het Nederlands met steun van de Nederlandse Taalunie als een facultatieve cursus werd aangeboden.

De tijd stond echter niet stil en geleidelijk aan was er behoefte ontstaan om dit materiaal dat voor $80 \%$ in het eerste studiejaar en voor $50 \%$ in de taalverwervingsmodule in het tweede studiejaar bachelorstudie werd gebruikt, te actualiseren. Voor deze ingrijpende veranderingen moesten zowel een team enthousiaste collega's als ook financiële middelen worden gevonden. Het project verkreeg de financiële steun van de Orde van den Prince, afdeling Diest. In september 2016 werd in de beide studiejaren een pilot met het nieuwe materiaal opgestart.

De studenten in het tweede studiejaar bachelor werkten in hun colleges taalverwerving met de geactualiseerde teksten en oefeningen van de audio-lexicale leergang Spreken is zilver-Module 2 die door het projectteam bestaande uit twee moedertaalsprekers van het Nederlands en de docent zelf grondig werden herzien. Studenten in het eerste studiejaar begonnen inmiddels te werken met ff $N L$ leren-Module $1 B$ (het wintersemester) en $f f N L$ leren - Module $2 B$ (het zomersemester), een geheel herschreven en uitgebreide versie van de leergang Spreken is zilver-Module 1.

$\mathrm{Na}$ het pilotjaar 2016/2017 werden de resultaten van de pilot omgezet in een nieuwe uitgave van de beide modules voor de studenten NVT in Olomouc. Daarnaast werd er ter overbrugging van de lange zomervakantieperiode van vier maanden zelfstudiemateriaal in de vorm van de aanvullende leergang Voor-Beelden. Klein Grammaticaal Overzicht $A B C(\& D)$ aangeboden. Dit materiaal werd vervolgens nabesproken in het eerste semester van het tweede studiejaar.

Voor beide modules van ff $N L$ leren geldt dat het aantal luister- en leesteksten die ook met nieuwe didactische werkvormen gepaard gaan, aanzienlijk is gegroeid. Bovendien staan er vele nieuwe lexicale oefeningen, liedjes, poëtische teksten en aforismen opgenomen. Hoewel dit materiaal op maat is ontwikkeld voor de studenten NVT in Olomouc, is het zeker - in ieder geval als een bron van inspiratie - ook bruikbaar voor andere NVT-instellingen in Centraal-Europa die in hun curriculum voor de taalverwerving een vergelijkbare ruimte aan liedjes en poëzie willen bieden. In Olomouc bestaat die ruimte in het eerste studiejaar in beide semesters uit 4 collegeblokken van 90 minuten per week (een semester heeft 12 collegeweken), in het tweede studiejaar is het de helft hiervan. 
Wat het structurele overzicht met betrekking tot het systematisch werken met liedjes betreft, wordt er in de beide studiejaren ook met de leergang Nederlied gewerkt. Aangezien in de leergang $f f N L$ leren grotere nadruk ligt op het werken met liedjes dan bij Spreken is zilver-Module 1, moest de opzet in de cursussen in het eerste studiejaar worden herzien. In plaats van het per semester afhandelen van 4 liedjes volgens het intensieve protocol van Thea van Gelder (zgn. Nederliedprotocol, zie Kř́ž 2016a) waarbij elk liedje acht- tot tienmaal met gevarieerde opdrachten gedurende een les van 90 minuten wordt afgespeeld en de huiswerkoefeningen in het begin van de volgende les worden nabesproken, worden er in de nieuwe versie slechts twee liedjes met dit protocol gepresenteerd. Het protocol blijft echter in het tweede studiejaar van toepassing wanneer de studenten in elk semester twee liedjes naar eigen keuze presenteren.

De overige liedjes in het eerste studiejaar worden in $f f N L$ leren-Module $1 B$ en $2 B$ behandeld door de docent aan de hand van een vereenvoudigd Nederlied "light"-protocol. Deze versie neemt slechts 30 minuten in beslag en beperkt zich tot werken met voorvragen en het invullen van de gatentekst met woorden, die in het boek meegegeven worden, waarna eventueel nog een korte oefening volgt. Dit biedt de ruimte voor het structureel inbouwen van een serie van 17 luisteroefeningen die gemiddeld 6-8 minuten duren en over de beide semesters verspreid, worden aangeboden. Deze luisterteksten worden Het luisterspel genoemd en zijn ingesproken door twee moedertaalsprekers van het Nederlands. De studenten moeten ze eerst beluisteren met hun ogen dicht, dan lezen ze de $8-10$ begripsvragen die ze na de volgende luisterronde moeten beantwoorden (Kříž 2016b: 229).

Hoe al deze op het luisteren en (mee)zingen gebaseerde elementen tot één geheel worden gebracht met de korte gedichten en aforismen opgenomen in $f f N L$ leren-Module $1 B$ en $2 B$, is weergegeven in figuur 1 en de tabellen 1 en 2 . Bovendien wordt in de eerste twee weken van het taalverwervingstraject een luisteroefening bij het Nederlandse alfabet als videofragment van 4 minuten op www.youtube.com aangeboden, samen met een transcriptie van de tekst. Dit videofragment vormt de aanloop tot werken met liedjes. Ook dit fragment wordt vervolgens met grote regelmaat gedraaid aan het begin van de taalverwervingscolleges, wanneer de docent eerst de aanwezigheid van de studenten registreert en vervolgens met het college van start gaat. Op deze manier worden de studenten gestimuleerd om naast de nieuwe woorden ook uitspraak, intonatie, spreektempo en grammaticale verschijnselen te oefenen door middel van het meezingen van deze bekende teksten. Met betrekking tot deze authentieke materiaalbronnen dient nog opgemerkt te worden, dat hoewel ze onder andere met het oog op eenduidig aanbod overwegend vanuit Nederland afkomstig zijn, de Vlaamse elementen naar aanleiding van de eigen keuzes van de studenten in het tweede studiejaar aan bod kunnen komen.

Zoals blijkt uit figuur 1, volgt er na het Nederlandse alfabet een systematische benadering van de overige cursuselementen. Terwijl het werken met liedjes een 


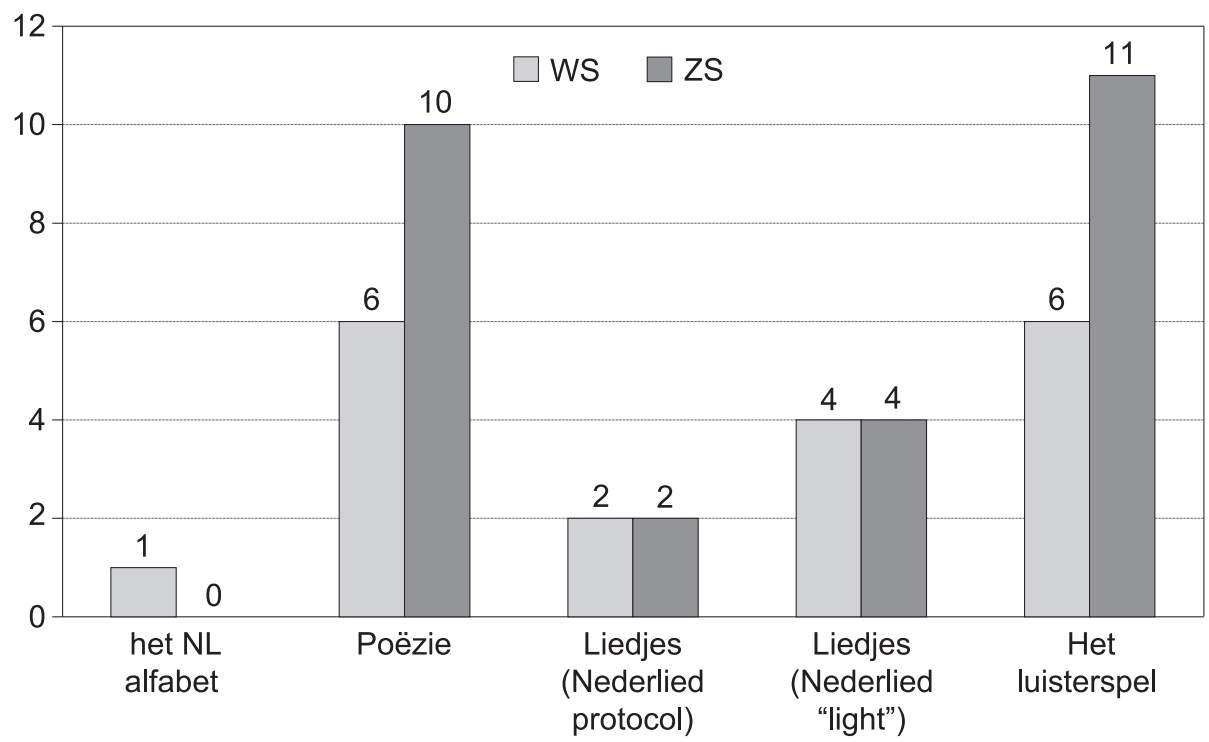

Figuur 1. Verdeling per semester van op authentiek materiaal gebaseerde cursuselementen (taalverwerving NVT in Olomouc, eerste studiejaar bachelor; de as links geeft het aantal afzonderlijke bronnen van authentiek materiaal aan $-\mathrm{WS}=$ wintersemester, $\mathrm{ZS}=$ zomersemester)

vast patroon van het behandelen van een identiek aantal liedjes in de beide semesters $(2$ liedjes met het volledige Nederlied-protocol en 4 liedjes met het Nederlied "light"'-protocol) bevat, wordt bij poëzie en het luisterspel in het zomersemester bijna het dubbele aantal gedichten en luisteroefeningen behandeld. Dit heeft te maken met de geleidelijke opbouw van de leergang $f f N L$ leren, waarbij bij de Module $1 B$ in het wintersemester nadruk op het leren werken met deze aanpak ligt in combinatie met het leggen van de stevige basis in het Nederlands. In Module $2 B$ worden vervolgens meer complexe taken aan de hand van langere (luister)teksten aan de studenten aangeboden.

Hoe de data weergegeven in figuur 1 zich in de afzonderlijke semesters verhouden tot het specifieke authentieke materiaal, blijkt uit de specificaties van de gedichten (naam gedicht vet gedrukt), liedjes (naam liedje in cursief) en het luisterspel (geen markering) in de tabellen 1 en 2. Met betrekking tot de liedjes bevatten deze overzichten nog een aanduiding welke versie van het Nederlied-protocol wordt gebruikt en of het liedje in Nederlied is opgenomen. Het luisterspel is net zoals de leergangen Spreken is zilver, Nederlied, ff NL leren of Voor-Beelden. Een Klein Grammaticaal Overzicht $A B C(\& D)$ afkomstig van SSALTO. 
Tabel 1. Overzicht liedjes en gedichten (wintersemester $1^{\mathrm{e}}$ studiejaar, ff NL leren-Module 1B)

\begin{tabular}{|c|c|c|c|}
\hline Naam gedicht/lied & Auteur & Aanpak liedje & In Nederlied? \\
\hline Berceuse Nr. 2 & $\begin{array}{l}\text { Paul van Ostaijen } \\
\text { (Polleken) }\end{array}$ & & \\
\hline het Nederlandse alfabet & $\begin{array}{l}\text { internet: www.you- } \\
\text { tube.com }\end{array}$ & & \\
\hline Luister... & Willem Hussem & & \\
\hline Flink zijn & $\begin{array}{c}\text { Paul de Leeuw } \\
\text { (Tekst/Muziek: R. } \\
\text { Long) }\end{array}$ & Nederlied "light" & JA \\
\hline Het luisterspel, afl. 1 & SSALTO & & \\
\hline Melopee & $\begin{array}{l}\text { Paul van Ostaijen } \\
\quad \text { (Polleken) }\end{array}$ & & \\
\hline Het is altijd lente & Peter de Koning & Nederlied "light" & NEE \\
\hline Het luisterspel, afl. 2 & SSALTO & & \\
\hline Het luisterspel, afl. 3 & SSALTO & & \\
\hline Voor de gelegenheid & Richard Minne & & \\
\hline Ik ben een meisje uit de stad & Wieteke van Dort & Nederlied "light" & JA \\
\hline Het luisterspel, afl. 4 & SSALTO & & \\
\hline Gedicht & $\begin{array}{l}\text { Paul van Ostaijen } \\
\text { (Polleken) }\end{array}$ & & \\
\hline Lieve Clara & Siel van der Ree & & \\
\hline Het luisterspel, afl. 5 & SSALTO & & \\
\hline $\begin{array}{l}\text { Ik heb geen zin om op te } \\
\text { staan }\end{array}$ & $\begin{array}{l}\text { HET (cover: Henk } \\
\text { Westbroek) }\end{array}$ & Nederlied "light" & NEE \\
\hline Het luisterpel, afl. 6 & SSALTO & & \\
\hline Ik houd van alle vrouwen & Hans de Booy & Nederlied & JA \\
\hline Per spoor & Guus Meeuwis & Nederlied & NEE \\
\hline
\end{tabular}

De weergave van de samenstelling van de bronnen van het authentieke materiaal in het zomersemester bevestigt het hierboven geschetste beeld, dat de studenten in het tweede semester in hogere mate (bijna in het dubbele aantal gevallen) zelfstandig met poëzie en het luisterspel moeten werken. 
Tabel 2. Overzicht liedjes en gedichten (zomersemester $1^{\mathrm{e}}$ studiejaar, $f f N L$ leren-Module $2 B$ )

\begin{tabular}{|c|c|c|c|}
\hline Naam gedicht/lied & Auteur & Aanpak & In Nederlied? \\
\hline Het licht is heel stil & J.C. van Schagen & & \\
\hline Ik weet & Jan G. Elburg & & \\
\hline Visser van Ma Yuan & Lucebert & & \\
\hline Het luisterspel, afl. 7 & SSALTO & & \\
\hline Het luisterspel, afl. 8 & SSALTO & & \\
\hline $\begin{array}{c}\text { Liedje van de luie } \\
\text { week }\end{array}$ & Hans Andreus & & \\
\hline Het luisterspel, afl. 9 & SSALTO & & \\
\hline Suzanne & Herman van Veen & Nederlied "light" & JA \\
\hline Het luisterspel, afl. 10 & SSALTO & & \\
\hline Schoolbord & C. Buddingh & & \\
\hline Fiets & Theo Olthuis & & \\
\hline Het luisterspel, afl. 11 & SSALTO & & \\
\hline Sonja van Veen & Brigitte Kaandorp & Nederlied "light" & NEE \\
\hline Het luisterspel, afl. 12 & SSALTO & & \\
\hline $\begin{array}{c}\text { Wij komen naar } \\
\text { jullie }\end{array}$ & $\begin{array}{c}\text { Clément Kala Mu- } \\
\text { lamba (vertaling: José } \\
\text { Aarts) }\end{array}$ & & \\
\hline Als niemand luistert & Jana Beranová & & \\
\hline Het luisterspel, afl. 13 & SSALTO & & \\
\hline Het luisterspel, afl. 14 & SSALTO & & \\
\hline Morgen is ze weg & Acda en de Munnick & Nederlied "light" & NEE \\
\hline $\begin{array}{l}\text { Marc groet ,s mor- } \\
\text { gens de dingen }\end{array}$ & Paul van Ostaijen & & \\
\hline Bekentenis & Ida Gerhardt & & \\
\hline Het luisterspel, afl. 15 & SSALTO & & \\
\hline De vluchteling & $\begin{array}{l}\text { Leonard Cohen/Her- } \\
\text { man van Veen }\end{array}$ & Nederlied "light" & JA \\
\hline Het luisterspel, afl. 16 & SSALTO & & \\
\hline Het luisterspel, afl. 17 & SSALTO & & \\
\hline Reiziger & Boudewijn de Groot & Nederlied & JA \\
\hline $\begin{array}{c}\text { Parijs, Berlijn, } \\
\text { Madrid }\end{array}$ & Boudewijn de Groot & Nederlied & JA \\
\hline
\end{tabular}


Uit de informatie weergegeven in figuur 1 en de tabellen 1 en 2 blijkt, dat binnen beide modules van de leergang $f f N L$ leren op een gestructureerde manier met authentiek materiaal in de vorm van liedjes en poëzie wordt gewerkt. Voordat echter conclusies met betrekking tot deze aanpak worden getrokken, is het noodzakelijk om stil te staan bij de manier, hoe met poëzie wordt gewerkt.

\subsection{Poëzie als nieuw element}

Aan het begin van de vorige paragraaf staat een kort overzicht van hoe in de taalverwerving NVT in Olomouc met liedjes en het luisterspel wordt gewerkt. Omdat bij de overstap van Spreken is zilver... naar ff NL leren in het eerste studiejaar in september 2016 poëzie in de cursus werd opgenomen, wordt de manier van werken met de gedichten en aforismen hier kort toegelicht.

Evenals bij de liedjes worden gedichten in eerste instantie als luistermateriaal gebruikt. De studenten doen hun boek dicht en luisteren met gesloten ogen naar hun docent, die de gedichten of aforismen voorleest. Daarna worden de associaties met de hele groep in het Nederlands en zo nodig ook in de moedertaal van de studenten nabesproken. Tijdens de volgende voorleesbeurt van de docent - vaak pas in het volgende college - mogen de studenten het gedicht meelezen. Daarna lezen ze het zelf voor. Deze keer wordt het gedicht in detail geanalyseerd en nabesproken.

Als voorbeeld hier het gedicht Melopee van Paul van Ostaijen dat in week 4 of 5 van het wintersemester wordt behandeld. De onderstreepte in het kader van de nabespreking in te vullen woorden staan alleen in het aanbod onder het gedicht vermeld. De studenten kunnen vervolgens zelf op het internet de verschillende opnames van het gedicht bekijken. Ook wordt er ruimte gegeven voor een nabespreking in kleine groepjes en met de docent.

Melopee (Paul van Ostaijen)

Onder de maan schuift de lange rivier

Over de lange rivier schuift moede de maandag

Onder de maan op de lange rivier schuift de kano naar zee

Langs het hoogriet

langs de laagwei

schuift de kano naar zee

schuift met de wuivende maan de kano naar zee

Zo zijn ze gezellen naar zee de kano de maan en de man

Waarom schuiven de maan en de man getweeën gedwee naar de zee

Vergeten? Kies dan uit:

schuift - moede - zee - maan - laagwei - langs - kano - samen - man gezellen 
Aan het voorbeeld van dit gedicht is het mogelijk om aan te tonen, dat ook in een vroege fase van het leren van een vreemde taal gedichten op een zinvolle, effectieve en didactisch verantwoorde manier tot de ontwikkeling van de studenten kunnen bijdragen.

\section{Conclusies}

Aan de hand van voorbeelden betreffende het gebruik van liedjes en poëzie in de cursussen taalverwerving NVT in Olomouc is hierboven aangetoond, dat het niet uitgesloten is om structureel liedjes en poëzie toe te passen. Alvorens de basale onderzoeksvraag Dient er in het universitair curriculum moderne vreemde talen ruimte te zijn voor (systematisch gebruik van) liedjes en poëzie? En zo ja, hoeveel? te beantwoorden, wordt er aandacht geschonken aan de deelvragen die het beeld specifieker maken.

Het antwoord op de deelvraag betreffende de redenen voor het systematisch toepassen van authentiek materiaal in de vorm van liedjes en poëzie hangt nauw samen met het verhogen van de motivatie van de studenten, die idealiter bepaalde onderdelen van hun cursus met hun keuzes kunnen beïnvloeden. Het gaat niet alleen over betere verankering van de leerstof, maar ook over verhoging van de effectiviteit van het onderwijs. Met betrekking tot het theoretisch en operationeel curriculum wordt geconcludeerd, dat er betrekkelijk veel ruimte voor het toepassen van authentiek materiaal in de vorm van liedjes en poëzie is. Het biedt vele mogelijkheden om op een zinvolle en plezierige manier een vreemde taal te leren. De derde deelvraag over de bevoegdheid om te beslissen over het gebruik van liedjes en poëzie biedt een eenvoudig antwoord. Wanneer de docent de ruimte van de vakgroep krijgt om liedjes en poëzie te implementeren, is de kans het grootst dat deze elementen effectief zullen fungeren. En als dit niet incidenteel, maar in een vorm van een vaste aanpak aan de hand van een standaard protocol gebeurt, zal zo'n benadering zeker vrucht afwerpen. Als de docent echter veel energie moet stoppen in het overtuigen van de collega's en eventuele andere betrokkenen dat het structureel toepassen van liedjes en poëzie geen tijdsverspilling is maar een toegevoegde waarde heeft, ontstaat er een gevaar dat hij zo'n gevecht tegen de windmolens opgeeft en zich tot de traditionele en voor sommigen misschien minder controversiële manieren van lesgeven blijft beperken. Dit kan echter op termijn tot gevolg hebben, dat zo'n docent minder enthousiast en gemotiveerd zijn taken gaat uitvoeren.

Gelukkig is zo'n duister scenario niet van toepassing op de situatie aan de in de casestudie in Olomouc beschreven onderwijs, waarin het structureel werken met liedjes en poëzie plaatsvindt. Tot de voordelen van het gebruiken van een leergang waarin met het toepassen van liedjes en poëzie rekening wordt gehouden, 
behoort dat de auteurs van de leergang het conceptuele deel van de planning van de inhouden van de colleges voor hun rekening hebben genomen.

Hier komt de primaire onderzoeksvraag terug: Dient er in het universitair curriculum moderne vreemde talen ruimte te zijn voor (systematisch gebruik van) liedjes en poëzie? En zo ja, hoeveel? Met de voorbeelden van de eigen onderwijspraktijk van de auteur van dit artikel is aangetoond, dat het niet alleen denkbaar, maar ook praktisch uitvoerbaar is om op een structurele en cyclische manier liedjes en poëzie te gebruiken. Ondanks het feit dat het wegens omstandigheden helaas onmogelijk was om deze algemene conclusie met behulp van een controlegroep beter te onderbouwen, blijft het gevoel over dat het goed kan gaan. Bovendien zijn er ook tastbare bewijzen. Zelfs zwakke studenten slagen er meestal in om het Certificaat Nederlands als Vreemde Taal in het zomersemester van hun eerste studiejaar op het A2-niveau ERK met succes af te leggen en na hun tweede studiejaar voegen ze er het B1-niveau aan toe.

Hiernaast zijn er ook andere tastbare resultaten. Zo hebben vanaf de zomer 2008 jaarlijks gemiddeld acht à negen studenten na hun tweede studiejaar een stage van drie maanden in bedrijven in België en Nederland gelopen. En daar hebben ze veel baat bij tijdens hun studieverblijven aan de partneruniversiteiten in de Lage Landen of in Centraal-Europa. Dankzij deze ervaringen vergroten ze bovendien hun kansen op een goede baan na of zelfs al tijdens hun studie NVT. Het succes van deze stageprojecten werd in de zomermaanden 2017 bekroond met het feit dat maar liefst vier van de negen stagiairs hun stage reeds na hun eerste studiejaar bachelor hebben afgerond. Dat was na afloop van het bovengenoemde pilotjaar van de leergang $f f N L$ leren, waarin aanzienlijk meer aan luistervaardigheid werd gedaan.

Deze successen onderstrepen de uitkomsten van eerdere onderzoeken. Uit deze blijkt, dat het werken met authentiek materiaal aangeboden in de vorm van liedjes kan bijdragen tot: het verschuiven van het accent binnen het onderwijs van een docent gecentreerde aanpak naar een (meer) student gecentreerde aanpak en tot toename van zinvol gebruik van de doeltaal tijdens de les door de studenten of het integreren van grammatica- of bijvoorbeeld realia-onderwijs op een natuurlijke manier. Bovendien draagt het werken met liedjes en poëzie bij tot verschillende aspecten van het leren van een vreemde taal. Dit houdt naast de pedagogische kant (de studenten beginnen niet alleen gemotiveerd aan hun studie, maar blijven ook tijdens de studie gemotiveerd), ook de taalverwervingskant van het onderwijs in (de studenten leren dankzij de liedjes en poëzie vele nieuwe woorden, uitdrukkingen en grammaticale verschijnselen die ze tijdens het zingen of voorlezen ook samen met de intonatiepatronen oefenen). Dankzij deze authentieke materiaalbronnen komt er tijdens het leren van een vreemde taal ruimte voor de kennismaking met verschillende maatschappelijke en culturele elementen die zich in deze materiaalbronnen weerspiegelen (Jauregi e.a. 2010; Kř́ž 2014). 
Het enorme potentieel van liedjes en poëzie voor het leren van moderne vreemde talen mag niet onderschat blijven en zou in de toekomst op een meer structurele en systematische wijze benut moeten worden.

\section{Bibliografie}

Blell, Gabriele, \& Karlheinz Helwig (red.) (1996): Bildende Kunst und Musik im FSU. Beiträge des Kongresses 1995 der Deutschen Gesellschaft für Fremdsprachenforschung in Halle. Frankfurt am Main: Peter Lang.

Boer, Berna de, e.a. (2012): Nederlands in actie. Methode NT2 voor hoogopgeleide anderstaligen ( $3^{\mathrm{e}}$ druk). Bussum: Uitgeverij Coutinho (met docentenhandleiding).

Engh, Dwayne (2013): "Why use music in English language learning? A survey of the literature". English Language Teaching 6:1, 113-127.

Gelder, Thea van, e.a. (1996): Nederlied. Liedjes bij het Nederlands als tweede en als vreemde taal. Apeldoorn: De Kangoeroe (met docentenhandleiding).

Goodlad, John I., e.a. (1979): Curriculum Inquiry: The Study of Curriculum Practice. New York: McGraw-Hill.

Janíková, Věra (2000): Methodik und Didaktik des Unterrichts Deutsch als Fremdsprache im Überblick. Aspekte des Hochschulfachs. Brno: Masarykova univerzita.

Jauregi, Kristi \& Milan Křriž (2010): "Het Nederlands en het EU-project NIFLAR (Networked Interaction in Foreign Language Acquisition and Research)". In: Jane Fenoulhet \& Jan Renkema (red.), Lage Landen Studies 1. Internationale neerlandistiek: een vak in beweging. Gent: Academia Press, 211-236.

Jauregi, Kristi, e.a. (2011): "Native/non-native speaker interactions through video-web communication: A clue for enhancing motivation?". Computer Assisted Language Learning 25:1, 1-19.

Klapwijk, Marion, \& Siel van der Ree (1998a): Spreken is zilver ... Module 1 (3 ${ }^{\mathrm{e}}$ druk). Amsterdam: Uitgeverij Boom.

Klapwijk, Marion, \& Siel van der Ree (1998b): Spreken is zilver ... Module 2 (3 ${ }^{\mathrm{e}}$ druk). Amsterdam: Uitgeverij Boom.

Kř́̌ž, Milan (2014): Onderwijs Nederlands in Centraal-Europa. Zes gevalsbeschrijvingen van effectieve NVT-instellingen. Utrecht: uitgave in eigen beheer.

Kříž, Milan (2015): “Op weg naar modern en effectief onderwijs NVT”. In: Bas Hamers (ed.), Pedagogiek van het Nederlands als Vreemde Taal. Centraal-Europese studenten en het Nederlands. Olomouc: Univerzita Palackého, 35-64.

Kř́žž, Milan (2016:) "Liedjes naar aanleiding van het Nederlied-protocol als middel voor het verhogen van de effectiviteit van het NVT-onderwijs in Centraal-Europa”. In: Bas Hamers \& Muriel Waterlot (ed.), Taalverwerving Nederlands ter discussie. Een kritisch boek over de taalverwerving Nederlands als vreemde taal. Lublin: Wydawnictwo KUL, 138-159.

Kř́žž, Milan (2016): "Leve de muziek! Aanzet tot onderzoek naar het potentieel van liedjes in het onderwijs Nederlands als vreemde taal”. Roczniki Humanistyczne 64:5, 221-238.

Kuiken, Folkert, \& Josine Burgers (2018): Dichter bij de taal. Nederlands leren met liedjes en poëzie. Amsterdam: Boom Uitgevers Amsterdam.

Kunert, Richard (2017): Music and Language Comprehension in the Brain. Nijmegen.

Patel, Aniruddh D. (2008): Music, Language, and the Brain. Oxford: Oxford University Press.

Ree, Siel van der, e.a. (2003a): ff NL leren. Elementaire cursus Nederlands als vreemde en als tweede taal-Module 1B. Voorburg/Drachten: Stichting Stimulering Audio-Lexicaal Taal Onderwijs. 
Ree, Siel van der, e.a. (2003b): ff NL leren. Elementaire cursus Nederlands als vreemde en als tweede taal-Module 2B. Voorburg/Drachten: Stichting Stimulering Audio-Lexicaal Taal Onderwijs.

Ree, Siel van der, e.a. (2017a): ff NL leren. Elementaire cursus Nederlands als vreemde en als tweede taal-Module 1B. Voorburg: Stichting Stimulering Audio-Lexicaal Taal Onderwijs.

Ree, Siel van der, e.a. (2017b): ff NL leren. Elementaire cursus Nederlands als vreemde en als tweede taal-Module 2B. Voorburg: Stichting Stimulering Audio-Lexicaal Taal Onderwijs.

Ree, Siel van der, e.a. (2017c): Voor-Beelden. Klein grammaticaal ABC(\&D). Voorburg: Stichting Stimulering Audio-Lexicaal Taal Onderwijs.

Reekmans, Karen, e.a. (2017): Vertaalde verbeelding. Muzische inspiratie voor taalstimulering in de meertalige klas. Antwerpen \& Apeldoorn: Garant.

Rosová, Veronika (2007): The Use of Music in Teaching English. Brno: Masarykova univerzita, MA thesis, laatst geraadpleegd op 28.11.2016 < https://is.muni.cz/th/84318/pedf_m/diploma_thesis_1.pdf.>.

\section{Websites}

(www1) <http://taaluniebericht.org/artikel/onderwijs/taalunie-docentencursus-nvt-en-neerlandistiek-actueler-en-breder $>$, laatst geraadpleegd op 1.05.2018.

(www2) $<$ https://didactiefonline.nl/artikel/hoe-grammatica-en-muziek-elkaar-beinvloeden>, laatst geraadpleegd op 1.05.2018.

(www3) < https://www.stichtingnob.nl/Over-NOB/Dit-doet-NOB/NOB-Bijscholing-2018/Creatiefmet-taal $>$, laatst geraadpleegd op 1.05.2018. 